\title{
Pedagogical leadership, and conflict of motives in commercial ECEC environments
}

\section{Lim, Sirene May-Yin}

Routledge

2019-01-01

Lim , S M-Y \& Lipponen , L 2019 , Pedagogical leadership, and conflict of motives in commercial ECEC environments . in S Cheeseman \& R Walker (eds), Pedagogies for Leading Practice. Thinking About Pedagogy in Early Childhood Education, Routledge, Abingdon, Oxon , pp. 165-181 .< https://www.taylorfrancis.com/books/e/9781351266925/chapters/10.4324/9781351266925-14 $>$

http://hdl.handle.net/10138/310294

unspecified

acceptedVersion

Downloaded from Helda, University of Helsinki institutional repository.

This is an electronic reprint of the original article.

This reprint may differ from the original in pagination and typographic detail.

Please cite the original version. 


\section{THINKING ABOUT PEDAGOGY IN EARLY CHILDHOOD EDUCATION}

Books in this series will serve as critical companions for senior undergraduate and postgraduate students conducting study and research in the field of early childhood education and care. As well as contributing to the thinking of teachers in a range of countries, these books will also be of interest to policy-makers and thinkers in a range of disciplines including health, welfare, sociology and community-building. Introducing new ideas and differing viewpoints from around the globe, texts take the reader beyond known cultural, ethical and geographical boundaries, to explore children's perspectives as a key component in early childhood pedagogy.

Each book in the series is divided into four interconnected sections: being alongside children, those who educate, families and communities, and policies and systems, to encompass the wide-ranging influences on contemporary pedagogical practice. Editors offer provocations to both link the chapters provided and offer directions for further thought. Grounded in sound empirical evidence, taking a global perspective, and born of critical and collaborative reflection, texts encourage readers to consider ideas which might be applied in their own learning, study and practice.

Series editors: Alma Fleet and Michael Reed

Titles in this series include:

PEDAGOGIES FOR CHILDREN'S PERSPECTIVES Catherine Patterson and Laurie Kocher

PEDAGOGIES FOR LEADING PRACTICE

Sandra Cheeseman and Rosie Walker

For more information about this series, please visit: www.routledge.com/education/series/TAPECE

\section{PEDAGOGIES FOR LEADING PRACTICE}

\author{
Edited by Sandra Cheeseman and \\ Rosie Walker
}

Routledge LONDON AND NEW YORK 
Rodd, J. (2013). Leadership in early childhood: A pathway to professionalism (4th ed.). Crows Nest, NSW: Allen \& Unwin.

Sahlberg, P. (2007). Education policies for raising student learning: The Finnish approach. Journal of Education Policy, 22(2), 147-171.

Sims, M. Forrest, R., Semann, A., \& Slattery, C. (2014). Conceptions of early childhood leadership: Driving new professionalism? International Journal of Leadership in Education: Theory and Practice, 18(2), 149-166. doi: $10.1080 / 13603124.2014 .962101$

Siraj-Blatchford, I. (2008). Understanding the relationship between curriculum, pedagogy and progression in learning in early childhood. Hong Kong Journal of Early Childhood, 7(2), 6-13.

Taguma, M. Litjens, I., \& Makowiescki, K. (2013). Quality matters in early childbood education and care: Finland 2012. Paris: OECD. doi:10.1787/ 97892617569-en

Waniganayake, M., Cheeseman, S., Fenech, M., Hadley, F., \& Shepherd, W. (2017). Leadership: Contexts and complexities in early childhood education (2nd ed.). South Melbourne: Oxford University Press.

\section{PEDAGOGICAL LEADERSHIP AND CONFLICT OF MOTIVES IN COMMERCIAL ECEC ENVIRONMENTS}

Sirene May-Yin Lim and Lasse Lipponen

Singapore's early childhood education and care (ECEC) landscape is still in its nascent phases of development towards becoming a knowledge-based profession. This chapter presents initial findings from a qualitative study of 24 ECEC leaders to discuss the various ways in which pedagogical leadership could be enacted within a neoliberal, marketised ECEC system within a meritocratic culture and an academically competitive education system (Lim, 2017b).

A marketised ECEC industry has the tendency to focus on market competitiveness, profit generation, business expansion, and shaping consumer choice through entrepreneurial innovations (Lloyd, 2012; Sumsion, 2006). In this study, we were interested in how such marketised environments, coupled with Singaporean families' general concern around children's academic achievement, would shape early childhood leaders' work. While literature has shown that pedagogical concerns should be central to an educational leader's work, oftentimes leaders are entangled in time-sensitive managerial and administrative tasks. There appears to be a struggle between two conflicting motives in ECEC leaders' work: conflict between the motives of engaging in child-centric pedagogical work or performing administrative and business-related tasks that serve a neoliberal market agenda. Applying Cultural-Historical Activity Theory (CHAT), we explore the complexities of pedagogical leadership within Singapore's commercialised ECEC environment. This chapter concentrates on ECEC leaders who manage child care centres or kindergartens, the two main types of ECEC provisions that are regulated and licensed in Singapore. 


\section{Understanding leadership in ECEC}

Leadership is, at present, not yet clearly defined within and across the global early childhood education and care (ECEC) sector (Rodd, 2013). There has been a traditional view of leadership that is associated with individual skills, characteristics, behaviours, and personal qualities in the leader (Nivala \& Hujala, 2002). According to Rodd (2013), ECEC leadership is not reducible to a checklist of qualities and skills due to its multi-dimensionality and complexity in practice involving staff, families and local communities with varying and diverse needs and expectations. In reality, a contextualised model of leadership (Hujala, 2013; Waniganayake, 2014) is needed so that leaders continually clarify and coconstruct with their team a common vision for the centre's work. To achieve this, leaders are to create ample learning opportunities for members of the organisation to produce positive results - that is, focused on the quality of children's learning and development, as well as the professional development and collaborative learning among teachers (Goffin \& Janke, 2013; Hujala, 2013; Siraj-Blatchford \& Manni, 2007; Waniganayake, Cheeseman, Fenech, Hadley, \& Shepherd, 2012).

There are rapidly changing expectations of ECEC leaders due to contesting views of ECEC's purpose in societies (Goffin \& Janke, 2013; Hujala, 2013). These 'change challenges' suggest a real imperative for the field to develop new and robust frameworks for leadership that can support people who are faced with challenges and have to initiate and facilitate change in more proactive ways (Fasoli, Scrivens, \& Woodrow, 2007). As such, investigations into ECEC leadership must be carefully contextualised to take into account the leader's position and autonomy accorded in decision-making, and the place and setting in which each leader operates (Waniganayake et al., 2012).

\section{The Singapore ECEC landscape and leadership}

In Singapore, the care and education of young children is provided by about 1800 licensed child care centres and kindergartens (Lim, 2017a). Child care centres provide the option of full-day programmes (children from 18 months) whereas kindergartens only offer half-day programmes (4-to-6-year-olds). All of these services are licensed but are largely operated by private commercial entities or not-for-profit social or religious organisations, except for less than 20 kindergartens run by the Ministry of Education (Goy, 2017). Before a child enters Primary One (the year of her/his seventh birthday), many families can choose between a few options to meet their young child's care and educational needs even though centre-based care is increasingly preferred as Singaporean families are more nuclear and grandparent care has become less available. In the last two years, the Early Childhood Development Agency (ECDA) has worked on increasing the number of child care places (i.e., full-day and flexible care and education for children from 18 months to 6 years) to meet families' demands, creating grants to support the larger child care operators to meet this goal. This has created a shortage of EC educators to staff the newly created centres (Lim, 2017b) and become an issue for EC leaders to contend with.

Despite its growth in number, Singapore's ECEC landscape is still in its nascent phases of development towards becoming a knowledgebased profession to replace its babysitters' image. Government policies in Singapore only started focusing on improving the professional quality of ECEC around the year 2000 (Lim, 2017a). Efforts started with an incremental raise in the minimum teacher and leader requirements, a recommended kindergarten curriculum framework, and more recently, the Singapore Preschool Accreditation Framework (SPARK) for programmes catering to 4-to-6-year-olds (Lim, 2017a). The SPARK Framework requires both child care centres and kindergartens with 4-to-6-year-olds to conduct annual self-appraisal using its Quality Rating Scale and volunteer for external accreditation when the centre is ready for external feedback. By October 2017, 40 per cent of pre-schools had received the SPARK certification (Early Childhood Development Agency, 2017a).

In Singapore, an ECEC leader is commonly called 'principal', 'supervisor' or 'centre director'. Before 2016, leaders were required to have a minimum of a professional Diploma in Early Childhood Care and Education - Teaching (typically 1200 hours part-time) and a Diploma in Early Childhood Care and Education - Leadership (typically 850 hours part-time). As part of the nation's strategy to incrementally raise quality in the ECEC sector, a new Advanced Diploma in Early Childhood Leadership (also 850 hours) has replaced the previous leadership diploma (Early Childhood Development Agency, 2016). Apart from these part-time professional diplomas, some principals would have completed their academic and professional teaching-cum-leadership preparation in a three-year full-time polytechnic diploma programme before turning 20 years old. This combined teaching and leadership programme has ceased to be available (Early Childhood Development Agency, 2016). 
Qualifications and training aside, many principals may have been handpicked for the role based largely on their teaching competencies and not because they were potentially good administrators and managers with strategic vision. So it is possible that inexperienced leaders struggle with their new role when given little mentoring or learning opportunities. Yet global literature tells us of the importance of competent leaders, because quality provision of ECEC for young children spending long hours in centre-based services is dependent on quality leadership (Muijs, Aubrey, Harris, \& Briggs, 2004; Siraj-Blatchford \& Manni, 2007).

Within Singapore's commercialised ECEC environment, ECEC leaders are potentially faced with managing different expectations and have to be accountable to a broad range of stakeholders: children and their families, teachers and staff, government agencies, external agencies and funders. They work within an industry that is not only short of teachers but is situated within a multifaceted context of a) increased quality demands by the licensing government agency; b) profit-driven expectations of their organisations, c) the academically competitive expectations of families, and d) the pedagogically child-centric intents of their teachers.

\section{Principal matters: a professional development programme}

In Singapore, ECEC teachers are reluctant to take on leadership roles due to reasons such as the lack of support and clarity of role as well as barriers within organisational cultures towards new ideas (Ebbeck, Saidon, Soh, \& Goh, 2014). ECEC leaders and their leadership practices have not been investigated sufficiently to be understood. We do not yet know enough about how they were selected, how well they are managing, what kinds of support they need to become better leaders, and about the challenges they face in their workplaces. Singapore has limited experience of how best to support ECEC leaders' continued learning within a largely private, and often commercial, sector.

Our study was funded by the Lien Foundation, a Singaporebased philanthropic organisation which created Principal Matters a six-month part-time professional development course designed to meet the learning needs of early childhood leaders with at least three years of leadership experience (commenced in 2016 with two cohorts annually). The Foundation aimed to fund six cohorts of about 25 principals each, all to be interviewed for selection into the unique programme. This study invited the first two cohorts of principals to participate in individual interviews and observations.

In this chapter, we describe how a group of Singaporean ECEC leaders have experienced their work, and especially the kinds of tensions and conflicts they faced as leaders. Our data are composed of 24 face-to-face interviews with ECEC principals whose ages ranged from 29 to 61 . The 24 participants had a range of 0 to 14 years of teaching experience and a range of 3 to 14 years of leadership experience. All the principals were females. These leaders worked in different kinds of settings with a range of 7 to 32 staff members. We learned that every setting had teachers who qualified outside of Singapore and a few centres were staffed by a majority of non-Singaporean teachers from China, Taiwan, Vietnam, Myanmar and the Philippines. There has been a significant shortage of teachers in the early childhood sector since the government encouraged more child care centres to be set up in recent years. Many ECEC centres have, therefore, hired teachers from overseas due to the shortage of teachers in Singapore. This phenomenon requires leaders to spend time familiarising foreigntrained teachers with local culture and expectations.

Our participants also worked within a range of environments and types of organisations. Seven of the centres were registered as not-forprofit kindergartens (mostly affiliated with churches) which provided half-day programmes and catered mainly to children from ages 4 to 6 ; one centre was undergoing a transition to offer both half-day 'kindergarten' and full-day 'child care' services within the same premises; 13 were for-profit providers and the remaining were not-for-profit; six of the centres were not part of a group or chain of centres managed by a single owner or organisation. The settings also varied by the type of neighbourhood in which they were situated - public housing estates, church compounds, houses with private gardens, and commercial office buildings. Different neighbourhoods cater to different social classes and communities and would require the leader to be able to relate to the specific clientele, speak their lingo and understand their needs.

\section{Leadership in Singapore ECEC: critical conflicts}

Given its largely privatised nature, varied settings and organisational structures, and diverse clientele and staff, EC leadership practice in Singapore is complex and involves everyday decision-making and problem-solving (Ang, 2012). This study uncovers the conflictual nature of 
leaders' everyday work and experience. All of these leaders experienced time-deprivation in juggling administrative, managerial, and pedagogical roles. A few talked about wanting to spend more time mentoring teachers but found themselves unable to do so because they are called to 'serve' their organisation by supporting other centres in the group.

Acting as an EC leader, doing and being a leader, is continuously filled with experiences and conditions resulting from external and internal forces acting in opposition to each other. To understand the multi-dimensional nature and experiences of our participants' work, we apply Vasilyuk's (1988) concept of critical conflicts. Working from within Cultural-Historical Activity Theory, Vasilyuk (1988; see also Engeström \& Sannino, 2011; Sannino, 2010) refers to critical conflicts as situations in which individuals face inner doubts when faced with contradictory motives. Critical conflicts are by their very nature personal, and they are expressed by means of emotionally and morally charged accounts. Feeling guilty and violated are common ways of experiencing critical conflicts (Engeström \& Sannino, 2011).

The act of experiencing involves both cognitive and socio-emotional aspects, and it can be manifested as interpreting, perceiving, or living through conflicts. How and what individuals experience emerges as an interaction between them and their social situation and culture. In other words, a given culture is not experienced the same way by different individuals or even by the same individuals at different times. While culture influences an individual's experiences, humans always contribute towards culture-creation as well, by exercising agency in shaping their own experience.

Critical conflicts are part of experiencing and struggling against the impossible.

According to Vasilyuk (1988, p. 32),

If one had to use one word only to define the nature of such situations one would have to say that they are situations of impossibility. Impossibility of what? Impossibility of living, of realising the internal necessities of life. The struggle against impossibility, the struggle to realise internal necessities - that is experiencing.

In Vasilyuk's (1988) theory of experiencing, struggles refer to conflicts between motives of a single person (see also Sannino, 2010). In many cases, critical conflicts are unsolvable by the subject alone. As stated by Sannino (2013, p. 48), 'Commonly, an individual without external support surrenders in front of the conflict and searches for easy ways out'. The following sections present four thematic strands that illustrate the kinds of conflicts faced by the leaders in this study.

\section{Managing a web of internal and external expectations}

The first vignette describes a principal experiencing the struggle of working within a large child care chain with a network of stakeholders with different expectations and competences. This principal had described herself as an octopus as she juggled with the multiple needs of the administration, teachers, children, and parents. Vignette 1 illustrates this.

\section{Vignette 1}

[I am] an octopus. Juggling administration, teachers and each teacher with their different sets of challenges, children [...] parents as well. My novice teachers are always very apprehensive about talking to parents. They always fear upsetting parents $[\ldots]$ because of that they didn't build a relationship with the parents... they didn't build a stable relationship. [When] anything happens, it is very hard for the parents... for me to gain back the trust. One forte I have, it seems to be so far across the year and it has been affirmed is that, I do have a good relationship with parents.

This leader experienced different role expectations when she interacted with the organisation's 'Headquarters' (HQ) staff and management. For many of our participants working in large organisations that manage more than 30 or 100 centres, their work involves working with different departments in the $\mathrm{HQ}$, managing different due dates for paperwork, facing fixed boundaries and guidelines. Such demands also place the principal in a 'sandwich', between the HQ's expectations and the expectations among his/her staff as well as the children and families served by the centre (Vignette 2).

Building on Vignette 1, Vignette 2 demonstrates how this same principal experiences a variety of forces that act in opposition to each other - the needs and interests of the organisation's various 
departments such as finance, human resources, marketing, curriculum specialists as well as those of the centre's novice teachers, more experienced teachers, non-teaching staff, the children their parents.

\section{Vignette 2}

I also feel that, it will be a bit of what we call a 'sandwich position' when [the] management rolls things out, we are the ones to deliver at ground level. Relationship with the team is very critical to see if the team can buy in the changes. But, so far, I would say is $50-50$ for me. The biggest challenge I have is, because I have a $[\mathrm{HQ}]$, anything I do may not just affect me, myself but it also affects the management [of the centre]. When I have a system in place to manage my teachers [and these are] preventive measures [because] if my teachers are not happy, they complain. And when they complain to the Ministry of Manpower, for example, [HQ] will definitely come after me because I am the representation. This is something that I feel very sandwiched in because (short pause) how do you expect me to run a centre when I don't have [control or] a preventive measure?

This situation is conflictual, as described by Vasilyuk (1988), and there seems to be no way that the leader can be disentangled from this web of interactions and varied responsibilities. This principal's experience is common among participants who work with a corporate $\mathrm{HQ}$ office.

\section{Asserting one's professional autonomy}

Over the past two decades, the primary and secondary schools in Singapore have replaced traditional school inspection with an external validation, with the aim of encouraging schools to be more reflexive $(\mathrm{Ng}, 2010)$. SPARK is the equivalent for ECEC programmes catering to 4-to-6-year-olds. To receive the SPARK certification, centres volunteer when they are ready for a thorough and careful assessment by external assessors from the ECDA. The assessors would use the Quality Rating Scale, interview and observe teachers, and produce a report detailing if the processes and systems need improvement. Recently, more pre-schools are recognising the value of going through SPARK even if it were for marketing purposes; while some of the not-for-profit operators receiving government funding have to complete the assessment within a stipulated timeframe (ECDA, 2017a). We learned that preparing for SPARK can sometimes be quite stressful for the principals and could generate conflicts within teams of ECEC educators.

Vignette 3 offers an illustration of how a principal had experienced the HQ management's distrust of her readiness in preparing for SPARK certification. The principal felt very upset and insulted when she recounted the experience. All she needed was to be recognised as a competent, autonomous and agentic subject who was an expert in her work.

\section{Vignette 3}

While preparing for SPARK, my [boss] did something which I really don't like. She called all [my peer principals in my area] to come down to my centre without informing me and they went into the classroom[s]. At that time, [lessons were still ongoing] but they tried to revamp all my learning centres. I really felt very upset [...] They said, 'Because [HQ's staff] said your centre will not get through [SPARK]. I know you are very busy. So, we [sent] the whole team down to help you'. [I felt] I was not being respected [as a principal] because when they came, all my teachers were stunned. [They would be] teaching [and the HQ staff would be] moving shelves and tables [...]. But I can't do anything because she was my direct superior and she sat in my centre for continuously three days to [supervise]. So, I could not say anything. I really felt upset on those three days. I am sorry to say[... .]

Vignette 3 is a clear example of what Vasilyuk (1988) referred to as critical conflict. 'I can't do anything because she is my direct superior...' represents a situation in which the principal faced doubts that paralysed her in face of contradictory motives: wanting to be autonomous in her work, yet not being able to do so. She experienced injustice but did not have the courage or any possibility of defending herself, so she could not extricate herself from the unfair and conflicting situation. In the principals' lives, such 
contradictory motives could appear to be so strong that they cannot be solved by the principals themselves. As stated by Vasilyuk (1988), the situation appeared to be a struggle against impossibility.

\section{Facing parents' woes and protecting one's staff}

Singapore's competitive academic landscape, its overall meritocratic ideology, high stakes testing for 12-year-olds, and an emphasis on global competitiveness, is partially responsible for a thriving commercial after-school tuition industry for school-going children (Gee, 2012; Lim, 2017b; Tan, 2017; Teng, 2015). It is well known that Singapore's education system is among the most highly regarded in the world because of its performance in the Trends in International Mathematics and Science Study (TIMSS) and the Programme for International Student Assessment (PISA). What is less discussed is the rising incidence of mental and emotional stress for children and teachers as well (Teng, 2015). Singapore parents may pay a significant sum for preschool and expect a return on their investment, nothing less than having their demands met. In a free market, parents who are not satisfied with a centre could enrol their child in another that may be more aligned with their needs. The following Vignette 4 demonstrates the motive arising from the conflict between defending and protecting the teachers against parents' demands and negative behaviours, and at the same time wanting to keep up the good relationship with parents because the centre is dependent on child enrolment.

\section{Vignette 4}

[Ways to get into the principal role] that's why I put a mirror there [on my desk]. You know when you're stressed, you can see the mirror. [To remind myself] when the parents are coming I will [...] especially when you know they are coming in means serious issues. [....] My role is to protect the teachers. I do have parents who come in and want to scream and shout [demanding to see my teachers] and I would say, 'I am sorry [my teacher is not available], what's happened?' It is always minor things.
Such conflicts often arise because ECEC educators have to negotiate between their own more child-centric educational beliefs and individual families' academic aspirations for their children.

\section{Supporting teachers' autonomy}

The following Vignette 5 is an example of the motive of conflict between controlling the pedagogical implementation of curriculum ('how do I keep track of the progress of each and every single class and how the teachers are doing') and supporting teachers' autonomy and agency in their work ('I am not here to police you, to catch you doing wrong. [Rather,] I am here to journey with you and enrich the curriculum together').

\begin{abstract}
Vignette 5
The challenge as a principal, I feel, is not just about tracking [progress] but helping [...] each teacher to understand and interpret what the (curriculum) framework actually means in their execution. Because we have zero [pre-created] lesson plans, which is a good thing. We have [a framework]. This means the teachers who come in need to work with frames of thinking and beginning teachers go 'What does that mean? What is a framework? [...]' So, I think my biggest challenge is that, in a very fluid way of planning, how do I keep track of the progress of each and every single class and how the teachers are doing. Yah, that would be my greatest struggle and challenge. I give a lot of autonomy to the teachers[...] My role will be going in and taking a look at what the classes are doing, [conducting] classroom observations. [...] (A lot of the observations are informal) because I want the teachers to see that I am not here to police you, to catch you doing wrong. [Rather,] I am here to journey with you and enrich the curriculum together. So, I cover [teachers'] shifts as well. I go in and [work with] the children as well.
\end{abstract}

While not common in our interview data, there were a few leaders working in organisations without prescriptive curricula who were 
confident about their role as curriculum leaders supporting their teachers' growth as curriculum designers.

\section{Ensuring profit and being innovative}

Singapore's ECEC system is a marketised system in which profit generation plays an important role. The need for profit may lead into a situation where centres and teachers, and the management are pitted against each other, favouring competition instead of collaboration. The following Vignette 6 shows that a critical conflict does not always lead to a dead end. Breaking away from the critical conflict opens up and expands a new horizon for enacting leadership.

In the vignette, the principal talks about wanting to do things differently and focus on delivering something that other centres cannot deliver. Simultaneously, she experiences that she is expected (she has) to take care of enrolment numbers and make a profit. There appears to be a critical conflict between these two goals doing things differently and making profit. This seems to be unsolvable by the principal alone. At first, the situation almost crippled her, but with external help and emotional support from her management, she was able to solve the conflict: in the words of Vasilyuk (1988) '. . she falls and rises again to continue the journey' (p. 32).

According to Engeström and Sannino (2011), critical conflicts may prevent individuals from engaging in a collective redesign of their material circumstances if collective resources are not mobilised for conflict resolution. Resolving critical conflicts requires one to find a new personal sense and to negotiate a new meaning for the initial situation. Such a resolution often takes the shape of personal liberation or emancipation.

\section{Vignette 6}

I have a lot of ideas. The thing is, [...] I already [reached] one of my goals, [... as] the youngest [centre in the group] but I want to be known for our curriculum delivery. I want to be known as the centre that does things differently. So, we have achieved one or two of that [...] I give credit to my teachers [...] Because we are so young as compared to all the other established [centres]. My [group supervisor] said, 'Don't worry about enrolment. Take care of your teachers, parents and all that. Enrolment will come.' Initially, I had so much pressure to meet the numbers, right? So, the focus was wrong. Then she said, 'You focus on the operations, focus on your people. Then, your [enrolment] numbers will come. Don't worry about it. [...] Numbers will come. Don't worry about this kind of thing'. So, I focused on that one as well. My teachers, like I said, it's not their job to meet the enrolment. It's their job to teach well.

It is encouraging to see EC leaders aspire to innovate as curriculum leaders and have an entrepreneurial mindset while being able to manage the centre like a business (Moloney \& Pettersen, 2017). While some may frown upon treating ECEC as a profit-making endeavor, this is perhaps a necessary skill that leaders need in Singapore's commercialised ECEC industry. The harsh reality is that centres can only continue to exist if they maintain healthy enrolment. Within such a marketised ECEC context, not only must leaders manage child enrolment numbers by building good relations with parents, work within the confines, constraints and expectations of their organisations and business owners, they must continue to improve the quality of the programmes. To do so, leaders must motivate their staff and must themselves be creative and innovative.

\section{Discussion}

Leadership is a dynamic process that is constructed relationally through multiple interactions within a cultural context, involving ongoing transformations of both the community and the self. Furthermore, it is through interactions that leadership is constructed, contested, negotiated and re-negotiated. It is constructed in relation to others, including teachers, children, parents, other professionals, and the wider community.

In this chapter, we have described how Singaporean ECEC leaders have talked about their work, the kinds of conflicts they have experienced, and the various ways in which they enact pedagogical leadership within a commercial ECEC system. Acting as a principal and doing and being a leader is continuously filled with conditions created by oppositional forces. To understand this leadership phenomenon, we applied Vasilyuk's (1988) idea of critical conflicts. 
The critical conflicts that we found among these principals were determined by their working upwards, downwards, outwards and inwards, with different stakeholders and their different expectations. All the participants in the study admittedly felt that they had to be someone to everyone because everyone that the leader came into contact with wanted something from her. Our study demonstrates that Singaporean ECEC leaders have to be aware of the expectations of multiple stakeholders such as parents, teachers, operators, and the government. ECEC leaders have to manage daily operations within the given confines of their organisation and setting. And they had to constantly (re)construct a vision for their programme's curriculum and pedagogy in response to external expectations (i.e., SPARK), or to the needs of the population that they served, as well as to broader societal views of children and families. As a consequence of working in this complex field of opposing forces, every leader experiences motives arising from conflicts.

In most cases, critical conflicts are something that cannot be solved by an individual subject (Vasilyuk, 1988); they easily lead to dead ends instead of positive transformation of unworkable practices, norms or rules. This is because conflicts are strongly intertwined with contradictions in collective activities within activity systems. Contradictions are not the same as problems or conflicts (Engeström, 1987); they are historically accumulating structural tensions within and among activity systems. Contradictions generate disturbances and conflicts, but also innovations that attempt to change the activity. As a result, to solve critical conflicts requires a collective redesign of activities. Vignette 6 represents such an attempt.

While not without methodological limitations, this study's in-depth interview approach enabled the participants to reflect on their personal and professional lives, in so far as their leadership role was concerned. And in so doing, our participants simultaneously articulated their experiences to themselves. Leaders do not often have the opportunity to talk about their work and their professional challenges to many people, at least not to fellow-educators who would understand their contextual situations. Many of these leaders spoke about walking the journey alone and how the 'Principal Matters' professional development programme was valuable for their sanity and professional growth. Within the programme, they found like-minded educators who reaffirmed their mission and provided some level of assurance that they were not alone in face of similar issues. At its best, discussing one's experiences with a researcher provides social and material support for the re-articulation and revision of these experiences, and making critical conflicts visible. Having significant conversations with other leaders can create the expansive potential of transforming the way in which these principals experience their lives as leaders.

\section{Concluding remarks}

Traditional views of leadership celebrate the anointing of a single person who can play the heroine or hero role in an organisation this model of leadership continues to dominate many early childhood settings and even in the larger Singapore education profession (Lambert, Zimmerman, \& Gardner, 2016). In this small-scale examination of the work of 24 ECEC leaders, we have provided a glimpse of the kinds of intricate webs or activity systems in which each of these leaders have had to navigate in order to learn to survive or thrive. Their daily decision-making and interactions shape their professional learning and in turn, they influence the nature of ECEC leadership within their particular cultural contexts and organisational settings.

\section{Acknowledgements}

This study reported here was funded by the Lien Foundation; and we are also grateful to the leaders who were willing to speak with us, without whom this study would have been impossible.

\section{References}

Ang, L. (2012). Vital voices for vital years: A study of leaders' perspectives on improving the early childhood sector in Singapore. Singapore: Lien Foundation.

Early Childhood Development Agency. (2016). Press release: Enhanced support for aspiring early childhood leaders through skillsfuture study awards. Retrieved from www.ecda.gov.sg/PressReleases/Pages/ ENHANCED-SUPPORT-FOR-ASPIRING-EARLY-CHILDHOOD-LEA DERS-THROUGH-SKILLSFUTURE-STUDY-AWARDS.aspx

Early Childhood Development Agency. (2017a). Press release: 40\% of pre schools now certified under Singapore preschool accreditation framework (SPARK). Retrieved from www.ecda.gov.sg/pressreleases/pages/40-per cent-of-preschools-now-certified-under-singapore-preschool-accredita tion-framework-(spark).aspx? controlmode=edit\&displaymode=design 
Ebbeck, M., Saidon, S., Soh, S., \& Goh, M. (2014). Readiness of early childhood professionals in Singapore to take on a leadership role. AsiaPacific Journal of Research in Early Childhood Education, 8(1), 79-98.

Engeström, Y. (1987). Learning by expanding: An activity-theoretical approach to developmental research. Helsinki: Orienta-Konsultit.

Engeström, Y., \& Sannino, A. (2011). Studies of expansive learning: Foundations, findings and future challenges. Educational Research Review, 5 (1), 1-24. doi:10.1016/j.edurev.2009.12.002

Fasoli, L., Scrivens, C., \& Woodrow, C. (2007). Challenges for leadership in Aotearoa/New Zealand and Australian early childhood contexts. In L. Keesing-Styles \& H. Hedges (Eds.), Theorising early childhood practice: Emerging dialogues. Sydney, NSW: Pademelon Press.

Gee, C. (2012). The educational "arms race": All for one, loss for all. Working paper 20. Singapore: Institute of Policy Studies.

Goffin, S., \& Janke, M. (2013). Early childhood education leadership development compendium: A view of the current landscape (2nd ed.). Retrieved from https://goo.gl/LT14HB

Goy, P. (2017, August 21). Big increase in child care places, MOE kindergartens: Teaching standards to be raised, spending to go up. The Straits Times Singapore. Retrieved from www.straitstimes.com/singapore/bigincrease-in-childcare-places-moe-kindergartens

Hujala, E. (2013). Contextually defined leadership. In E. Hujala, M. Waniganayake \& J. Rodd (Eds.), Researching leadership in early childhood education (pp. 47-60). Tampere: Tampere University Press.

Lambert, L., Zimmerman, D. P., \& Gardner, M. E. (2016). Liberating leadership capacity: Pathways to educational wisdom. New York: Teachers College Press.

Lim, S. (2017a). Early childhood care and education in Singapore: Context and prevailing issues. In M. Fleer \& B. van Oers (Eds.), International handbook of early childbood education, Volume 1. Amsterdam: Springer.

Lim, S. (2017b). Marketization and corporatization of early childhood care and education in Singapore. In M. Li, J. Fox \& S. Grieshaber (Eds.), Contemporary issues and challenge in early childhood education in the Asia-Pacific region (pp. 17-32). Singapore: Springer.

Lloyd, E. (2012). The marketisation of early years education and child care in England. In L. Miller \& D. Hevey (Eds.), Policy issues in the early years. London: Sage Publications.

Moloney, M., \& Pettersen, J. (2017). Early childhood education management: Insights into business practice and leadership. Abingdon, Oxon: Routledge.

Muijs, D., Aubrey, C., Harris, A., \& Briggs, M. (2004). How do they manage? A review of the research on leadership in early childhood. Journal of Early Childhood Research, 2(2), 157-169.

$\mathrm{Ng}, \mathrm{P}$. T. (2010). The evolution and nature of school accountability in the Singapore education system. Educational Assessment, Evaluation and Accountability, 22(4), 275-292.
Nivala, V., \& Hujala, E. (Eds.). (2002). Leadership in early childhood education, cross cultural perspectives. Oulu: Department of Educational Sciences and Teacher Education, Early Childhood Education, University of Oulu.

Rodd, J. (2013). Leadership in early childhood: The pathway to professionalism (4th ed.). Sydney, NSW: Allen \& Unwin.

Sannino, A. (2013). Critical transitions in the pursuit of a professional object: Simone de Beauvoir's expansive journey to become a writer. In A. Sannio \& V. Ellis (Eds.), Learning and collective creativity: Activitytheoretical and sociocultural studies. New York: Routledge.

Sannino, A.-L. (2010). Teachers' talk of experiencing: Conflict, resistance and agency. Teaching and Teacher Education, 26, 838-844.

Siraj-Blatchford, I., \& Manni, L. (2007). Effective leadership in the early years sector: The ELEYS study. London: Institute of Education, University of London.

Sumsion, J. (2006). The corporatisation of Australian childcare: Towards an ethical audit and research agenda. Journal of Early Childhood Research, 4(2), 99-120. doi:10.1177/1476718X06063531

Tan, C. T. (2017). Enhancing the quality of kindergarten education in Singapore: Policies and strategies in the 21st century. International Journal of Child Care and Education Policy, 11, 7. doi:10.1186/s40723-017-0033-y

Teng, A. (2015, July 4). Starting from pre-school, parents sending kids for classes in race to keep up with peers. The Straits Times Singapore. Retrieved from www.straitstimes.com/singapore/education/starting-frompre-school-parents-sending-kids-for-classes-in-race-to-keep-upon

Vasilyuk, F. (1988). The psychology of experiencing. Moscow: Progress.

Waniganayake, M. (2014). Being and becoming early childhood leaders: Reflections on leadership studies in early childhood education and the future leadership research agenda. Journal of Early Childhood Education Research, 3(1), 65-81.

Waniganayake, M., Cheeseman, S., Fenech, M., Hadley, F., \& Shepherd, W. (2012). Leadership: Contexts and complexities in early childhood education. South Melbourne: Oxford University Press. 